\title{
Growth-phase dependence of susceptibility to antimicrobial peptides in Staphylococcus aureus
}

\begin{abstract}
Correspondence
Hitoshi Komatsuzawa

hkomatsu@dent.

kagoshima-u.ac.jp
\end{abstract}

Received 17 August 2010

Revised 24 February 2011

Accepted 6 March 2011

\author{
Miki Matsuo, ${ }^{1}$ Yuichi Oogai, ${ }^{1}$ Fuminori Kato, ${ }^{2}$ Motoyuki Sugai ${ }^{2}$ \\ and Hitoshi Komatsuzawa ${ }^{1}$ \\ ${ }^{1}$ Department of Oral Microbiology, Kagoshima University Graduate School of Medical and \\ Dental Sciences, Kagoshima 890-8544, Japan
${ }^{2}$ Department of Bacteriology, Hiroshima University Graduate School of Biomedical Sciences, Hiroshima 734-8553, Japan

\begin{abstract}
Bacterial cell surface charge is responsible for susceptibility to cationic antimicrobial peptides. Previously, Staphylococcus aureus $d l t$ and $m p r F$ were identified as factors conferring a positive charge upon cell surfaces. In this study, we investigated the regulation of cell surface charge during growth. Using a group of $S$. aureus MW2 mutants, which are gene-inactivated in 15 types of two-component systems (TCSs), we tested $d \mathrm{ltC}$ and $m p r F$ expression and found that two TCSs, aps and agr, were associated with $d l t C$ and $m p r F$ expression in a growth phase-dependent manner. The first of these, aps, which had already been identified as a sensor of antimicrobial peptides and a positive regulator of $d / t$ and $m p r F$ expression, was expressed strongly in the exponential phase, while its expression was significantly suppressed by agr in the stationary phase, resulting in higher expression of $d l t C$ and $m p r F$ in the exponential phase and lower expression in the stationary phase. Since both types of expression affected the cell surface charge, the susceptibility to antimicrobial peptides and cationic antibiotics was changed during growth. Furthermore, we found that the ability to sense antimicrobial peptides only functioned in the exponential phase. These results suggest that cell surface charge is tightly regulated during growth in S. aureus.
\end{abstract}

\section{INTRODUCTION}

Staphylococcus aureus is a well-known major pathogen in humans. S. aureus produces many toxins and exoenzymes to cause various suppurative diseases, food poisoning and toxic shock syndrome (Foster, 2004; Lowy, 1998; Manders, 1998). Furthermore, strains isolated clinically, especially meticillin-resistant $S$. aureus (MRSA), exhibit multiple antibiotic resistance (Deurenberg et al., 2007; Grundmann et al., 2006), resulting in serious problems with regard to therapy of $S$. aureus infectious disease. Recently, besides these virulence factors, $S$. aureus has also been found to possess the ability to produce several factors that protect against host-derived innate immune factors, such as complement, antibodies and neutrophils, as well as recently recognized innate immune antimicrobial peptides, such as LL-37 and defensins (Foster, 2005; Rooijakkers et al., 2005).

Human antimicrobial peptides are one of the innate immune factors and are produced in various tissues and organs, such as the skin, lung and intestines (Ganz et al.,

Abbreviations: $\mathrm{CP}$, chloramphenicol; hBD, human beta-defensin; MRSA, meticillin-resistant S. aureus; TC, tetracycline; TCS, two-component system.
1985; Ganz \& Lehrer, 1995; Lehrer \& Ganz, 1999; Selsted \& Ouellette, 2005; Zaiou \& Gallo, 2002). The most wellknown antimicrobial peptides are the defensins. Defensins are classified into two types: alpha-defensins from neutrophils and Paneth cells, and beta-defensins from epithelial cells (Cunliffe, 2003; Ganz et al., 1985; Ganz \& Lehrer, 1995). Another major peptide is CAP18/LL37, which is found in neutrophils and epithelial cells (Larrick et al., 1995; Ramanathan et al., 2002; Zaiou \& Gallo, 2002). These cationic peptides are electrostatically attracted to bacterial cell surfaces. Then, the peptides interact with membrane lipids, causing membrane permeabilization and leading to the formation of pores or gaps in the membrane. Recently, some diseases such as Crohn's disease (Fellermann et al., 2003a; Wehkamp et al., 2002), atopic dermatitis (Fellermann et al., 2003b; Ong et al., 2002) and Kostmann's disease (Pütsep et al., 2002) have been demonstrated to be associated with increased microbial infection because antimicrobial peptide production is decreased in these patients. Therefore, antimicrobial peptides are believed to be critical for host defence systems.

Previously, we showed that susceptibility to antimicrobial peptides, including beta-defensin-3 and LL37, differs substantially among 497 clinically isolated strains (Ouhara 
et al., 2008). We also showed that bacterial cell surface charge is one of the factors that affects susceptibility to antimicrobial peptides. To date, in S. aureus, three types of mechanism that affect susceptibility to antimicrobial peptides have been identified. These are (1) trapping defensins by binding to staphylokinase (Braff et al., 2007; Jin et al., 2004), (2) digestion of peptides by proteinase (Sieprawska-Lupa et al., 2004), and (3) changing the bacterial cell surface charge via $d l t$ and $m p r F$ (Li et al., 2007a; Peschel et al., 1999, 2001). mprF was first identified as $\mathrm{fmt} C$, which was shown to affect the meticillin-resistance level in MRSA (Komatsuzawa et al., 2001). Among the above mechanisms, cell surface charge is considered to play a significant role in determining susceptibility to antimicrobial peptides, because $d l t$ or $m p r F$ inactivation results in a high level of susceptibility to these peptides. Recently, Aps, one of the two-component systems (TCSs), has been shown to sense antimicrobial peptides and regulate the expression of $d l$ and $m p r F$ (Li et al., 2007a, b).

In this study, we investigated the regulation of $d l t$ and $m p r F$ expression mediated by TCSs during growth in $S$. aureus. Also, we investigated the interaction of $d l t$ and $m p r F$ expression with bacterial surface charge and susceptibility to cationic antibacterial agents.

\section{METHODS}

Bacterial strains and growth conditions. The bacterial strains used in this study are listed in Table 1. S. aureus was grown in Trypticase Soy Broth (TSB; Beckton Dickinson Microbiology Systems). Tetracycline (TC; $10 \mu \mathrm{g} \mathrm{ml}^{-1}$ ) or chloramphenicol (CP; $10 \mu \mathrm{g} \mathrm{ml}^{-1}$ ) for S. aureus was added when necessary. Fifteen sets of TCS mutants in $S$. aureus MW2, which had been constructed previously (Matsuo et al., 2010), were used in this study.

Construction of insertion-inactivated mutants. In this study, we constructed the agr-and aps-inactivated mutants in S. aureus TY34 by a method described previously (Komatsuzawa et al., 2004; Matsuo et al., 2010). We also tried to construct an agr-aps double mutant in MW2, but this was not successful. For the complementation experiment, we constructed an agrA-inactivated mutant by the method described above. Since we had previously constructed the agr mutant, which inactivated agrCA (Matsuo et al., 2010), we first constructed a plasmid harbouring all of the agr genes, although this failed. agr $A$, encoding a response regulator, is the last gene in an operon consisting of four genes (agrBDCA) (Novick, 2003). We checked that the agrA mutant showed a phenotype similar to that of the $\operatorname{agr} C A$ mutant. The DNA fragment of apsR or agrA amplified with specific primers was cloned into pCL15, an E. coli-S. aureus shuttle vector with a Pspac promoter (Luong \& Lee, 2006). The plasmid was electroporated into RN4220. Then, the plasmid was transduced to the agr or aps mutant by phage 80 alpha by a method described previously (Komatsuzawa et al., 2004). The primers used for the construction of plasmids are listed in Table 2.

Quantitative analysis of gene expression during $\mathbf{S}$. aureus growth. A small sample of $S$. aureus cultured overnight was inoculated into fresh TSB. Then, S. aureus cells were grown at $37^{\circ} \mathrm{C}$ with shaking, and bacterial cells in various phases were collected. Total RNA was extracted from bacterial cells with a FastRNA Pro Blue kit (MP Biomedicals) in accordance with the manufacturer's protocol. One microgram of total RNA was reversetranscribed to cDNA using a First Strand cDNA Synthesis kit (Roche). Using cDNA as template DNA, quantitative PCR was performed using a LightCycler system (Roche). Primers for $d l t C$, $m p r F, a p s R$ and agrA were constructed and used to determine the optimal conditions for analysis of their expression. The amount of gyrA was used as an internal control. Primers for each TCS and $g y r A$ are shown in Table 2.

Assay to determine the antibacterial activity of antimicrobial peptides. An antibacterial assay was performed following a protocol described previously (Midorikawa et al., 2003). Briefly, S. aureus strains in the appropriate phase were harvested, washed with PBS and resuspended in $10 \mathrm{mM}$ sodium phosphate buffer $(\mathrm{PB})$. The bacterial suspension was diluted to $10^{7}-10^{8}$ cells $\mathrm{ml}^{-1}$ with $\mathrm{PB}$, and $10 \mu \mathrm{l}$ of the bacterial suspension $\left(10^{5}-10^{6}\right.$ cells) was inoculated into $500 \mu \mathrm{PB}$ with or without antimicrobial peptides [human beta-defensin (hBD)1, -2 and -3 ; Peptide Institute Inc.] and incubated aerobically for $2 \mathrm{~h}$ at $37^{\circ} \mathrm{C}$. Dilutions of the reaction mixture $(100 \mu \mathrm{l})$ were plated on agar medium and incubated at $37{ }^{\circ} \mathrm{C}$ overnight. The c.f.u. was determined as the total number of colonies identified on each plate. The antibacterial effect was calculated as the ratio of the number of cells surviving after exposure to antimicrobial peptides (survival rate, \%) to the total number of bacteria incubated in a control PB solution.

Cytochrome $\boldsymbol{c}$ binding assay. To evaluate the bacterial surface charge, we used a cytochrome $c$ binding assay as described elsewhere (Peschel et al., 1999). Bacterial cells collected in the appropriate phase were adjusted to a concentration of $10^{10} \mathrm{ml}^{-1}$ in $10 \mathrm{mM} \mathrm{PB}$ ( $\mathrm{pH}$ 6.8), and then cytochrome $c$ (Sigma Aldrich) was added to the bacterial suspension at a final concentration of $250 \mu \mathrm{g} \mathrm{ml}^{-1}$. After $10 \mathrm{~min}$ incubation at room temperature, centrifugation at 15000 r.p.m. for 5 min was performed, and the supernatant absorbance was measured at $530 \mathrm{~nm}$. The absorbance value obtained compared with that without bacterial cells was calculated as the absorption ratio, reflecting the bacterial surface charge.

Assay of susceptibility to cationic antibacterial agents. Positively charged antibacterial agents (gentamicin, nisin, polymyxin $\mathrm{B}$, gramicidin $\mathrm{S}$, indolicidin and vancomycin) were obtained from Sigma Aldrich. Bacterial cells collected in the exponential or stationary phase were suspended in $10 \mathrm{mM}$ PB ( $\mathrm{pH} \mathrm{6.8)}\left(10^{5}-10^{6}\right.$ cells $500 \mu \mathrm{l}^{-1}$ ) with or without antibacterial agent. Nisin (final concentration $\left.1 \mu \mathrm{g} \mathrm{ml}^{-1}\right)$, polymyxin $\mathrm{B}\left(1 \mu \mathrm{g} \mathrm{ml}^{-1}\right)$, gramicidin $\mathrm{S}$ $\left(1 \mu \mathrm{g} \mathrm{ml}^{-1}\right)$, indolicidin $\left(0.1 \mu \mathrm{g} \mathrm{ml}^{-1}\right)$, gentamicin $\left(4 \mu \mathrm{g} \mathrm{ml}^{-1}\right)$ and vancomycin $\left(2 \mu \mathrm{g} \mathrm{ml}^{-1}\right)$ were added to the buffer. After $10 \mathrm{~min}$ (gentamicin and vancomycin) or $2 \mathrm{~h}$ (nisin, indolicidin, polymyxin and gramicidin S) of incubation at $37{ }^{\circ} \mathrm{C}$, the reaction mixture was diluted and plated on trypticase soy agar (TSA). The number of c.f.u. was counted and used to calculate the proportion of bacteria that survived by comparing with the c.f.u. in the absence of antibacterial agents.

Analysis of antimicrobial peptide sensing in S. aureus. Bacterial cells collected in the appropriate phase were suspended in $10 \mathrm{mM} \mathrm{PB}$ ( $\mathrm{pH}$ 6.8) at a final concentration of $10^{9} \mathrm{ml}^{-1}$. Then, hBD1, -2 and -3 at a final concentration of $10(\mathrm{hBD} 1)$ or $2.5 \mu \mathrm{g} \mathrm{ml}^{-1}(\mathrm{hBD} 2, \mathrm{hBD} 3)$ was added to the bacterial suspension, followed by incubation for 30 min at $37^{\circ} \mathrm{C}$. After centrifugation, total RNA was extracted using the method described above. Then, cDNA synthesis and quantitative PCR were performed using the methods described above. To check the viability of the bacterial cells exposed to antimicrobial peptides, the reaction mixtures were diluted and plated on TSA. After $24 \mathrm{~h}$ of incubation, the number of c.f.u. was recorded. The antibacterial effect was estimated by determining the rate of survival of cells in comparison with the total number of cells added. 
Table 1. Strains and plasmids used in this study

\begin{tabular}{|c|c|c|c|c|}
\hline $\begin{array}{l}\text { Strain or } \\
\text { plasmid }\end{array}$ & Gene ID* & Gene name & Characteristics & Reference or source \\
\hline \multicolumn{5}{|l|}{ Strains } \\
\hline MW2 & - & - & Clinical strain, meticillin-resistant $(m e c+)$ & Baba et al. (2002) \\
\hline FK61 & MW0198-99 & Unassigned & MW0199:: pCL52.1 in MW2, TC $^{\mathrm{r}} \dagger$ & Matsuo et al. (2010) \\
\hline FK62 & MW0236-37 & lytSR & lytS::pCL52.1 in MW2, $\mathrm{TC}^{\mathrm{r}}$ & Matsuo et al. (2010) \\
\hline FK64 & MW0621-22 & apsRS/graRS & apsR::pCL52.1 in MW2, TC ${ }^{\mathrm{r}}$ & Matsuo et al. (2010) \\
\hline FK65 & MW0667-68 & saeRS & saeR:: pCL52.1 in MW2, $\mathrm{TC}^{\mathrm{r}}$ & Matsuo et al. (2010) \\
\hline FK66 & MW1208-09 & Unassigned & MW1208::pCL52.1 in MW2, TC $^{r}$ & Matsuo et al. (2010) \\
\hline FK67 & MW1304-05 & arlRS & $\operatorname{arlR}::$ pCL52.1 in MW2, $\mathrm{TC}^{\mathrm{r}}$ & Matsuo et al. (2010) \\
\hline FK68 & MW1445-46 & $\operatorname{srr} A B$ & srrA ::pCL52.1 in MW2, $\mathrm{TC}^{\mathrm{r}}$ & Matsuo et al. (2010) \\
\hline FK69 & MW1636-37 & phoPR & phoP::pCL52.1 in MW2, $\mathrm{TC}^{\mathrm{r}}$ & Matsuo et al. (2010) \\
\hline FK71 & MW1789-90 & Unassigned & MW1790::pCL52.1 in MW2, TC $^{\mathrm{r}}$ & Matsuo et al. (2010) \\
\hline FK72 & MW1824-25 & vraSR & $\operatorname{vraS}:$ :pCL52.1 in MW2, $\mathrm{TC}^{\mathrm{r}}$ & Matsuo et al. (2010) \\
\hline FK73 & MW1962-63 & $\operatorname{agrCA}$ & $\operatorname{agrC}:: \mathrm{pCL} 52.1$ in MW2, $\mathrm{TC}^{\mathrm{r}}$ & Matsuo et al. (2010) \\
\hline FK74 & MW2002-03 & $k d p D E$ & $k d p D::$ pCL52.1 in MW2, $\mathrm{TC}^{\mathrm{r}}$ & Matsuo et al. (2010) \\
\hline FK75 & MW2282-83 & $h s s R S$ & $h s s R::$ pCL52.1 in MW2, $\mathrm{TC}^{\mathrm{r}}$ & Matsuo et al. (2010) \\
\hline FK76 & MW2313-14 & $n r e B C$ & $n r e B::$ pCL52.1 in MW2, $\mathrm{TC}^{\mathrm{r}}$ & Matsuo et al. (2010) \\
\hline FK77 & MW2544-45 & Unassigned & MW2545::pCL52.1 in MW2, TC $^{\mathrm{r}}$ & Matsuo et al. (2010) \\
\hline MM11 & MW1963 & $a g r A$ & $\operatorname{agr} A:: \mathrm{pCL} 52.1$ in MW2, $\mathrm{TC}^{\mathrm{r}}$ & This study \\
\hline MM12 & MW0621 & $a p s R$ & pMM12 in FK64, TC ${ }^{r}, \mathrm{CP}^{r_{\ddagger}}$ & This study \\
\hline MM14 & MW1963 & $\operatorname{agr} A$ & pMM14 in MM11, $\mathrm{TC}^{\mathrm{r}}, \mathrm{CP}^{\mathrm{r}}$ & This study \\
\hline TY34 & - & - & Clinically isolated strain, impetigo & This study \\
\hline MM15 & MW0621-22 & apsRS/graRS & apsR:: pCL52.1 in TY34, $\mathrm{TC}^{\mathrm{r}}$ & This study \\
\hline MM16 & MW1962-63 & $\operatorname{agr} C A$ & $\operatorname{agrC}:: \mathrm{pCL} 52.1$ in TY34, $\mathrm{TC}^{\mathrm{r}}$ & This study \\
\hline RN4220 & - & - & Laboratory strain, meticillin-sensitive $\left(\mathrm{mec}^{-}\right)$ & Kreiswirth et al. (1983) \\
\hline TY1355 & - & - & Clinically isolated strain, SSSS $\$$ & This study \\
\hline TY1741 & - & - & Clinically isolated strain, impetigo & This study \\
\hline TF2890 & - & - & Clinically isolated strain, atopy & This study \\
\hline TF2988 & - & - & Clinically isolated strain, sepsis & This study \\
\hline TF3483 & - & - & Clinically isolated strain, sepsis & This study \\
\hline \multicolumn{5}{|l|}{ Plasmids } \\
\hline pCL52.1 & & - & S. aureus integration vector, thermosensitive, $\mathrm{TC}^{\mathrm{r}}$ in $S$. aureus & Sau et al. (1997) \\
\hline pCL15 & & - & E. coli-S. aureus shuttle vector, $\mathrm{AP}^{\mathrm{r}} \|$ in $E$. coli, $\mathrm{CP}^{\mathrm{r}}$ in $S$. aureus & Luong \& Lee (2006) \\
\hline pMM11 & & $\operatorname{agr} A$ & PCR fragment for the agr mutant/pCL52.1 & \\
\hline pMM12 & & $a p s R$ & PCR fragment for the apsR complementation/pCL15 & \\
\hline pMM14 & & $\operatorname{agr} A$ & PCR fragment for the $a g r A$ complementation/pCL15 & \\
\hline
\end{tabular}

${ }^{*}$ Gene ID in S. aureus MW2.

$\dagger$ Tetracycline resistance.

¥Chloramphenicol resistance.

$\S$ Staphylococcal scalded skin syndrome.

IIAmpicillin resistance.

\section{RESULTS}

\section{dlt expression in 15 sets of TCS mutants}

Aps/Gra has been reported to be a factor controlling $d l t$ and mprF expression (Kraus et al., 2008; Li et al., 2007a). To determine whether other factors are involved in the regulation of $d l t$ and $m p r F$ expression, we investigated the expression of $d l t C$ and $m p r F$ in 15 sets of TCS mutants in $S$. aureus MW2 in the exponential and stationary phases (Fig. 1). Since the dlt operon is composed of four genes, $d l t A-D$, we investigated $d l t C$ expression to determine $d l t$ expression. The results showed that $d l t C$ expression was decreased in the aps mutant in the exponential phase compared with that in the wild-type and other mutants, but that the expression in the aps mutant in the stationary phase was similar to that of the other mutants, except for the agr mutant. In the agr mutant, $d l t C$ expression in the stationary phase was significantly higher than that of the wild-type and other mutants, but expression in the agr mutant in the exponential phase was similar to that of the others, except for the aps mutant. We also investigated $m p r F$ expression in TCS mutants, and obtained results that were similar to those for $d l t C$ expression (data not shown). 
Table 2. Primers used in this study

\begin{tabular}{|c|c|c|c|}
\hline \multirow[t]{2}{*}{ Gene ID* } & \multirow[t]{2}{*}{ Gene name } & \multicolumn{2}{|c|}{ Specific primer for quantitative PCR } \\
\hline & & Forward & Reverse \\
\hline MW0006 & gyrA & $5^{\prime}$-aag gtg ttc gct taa ttc gc- $3^{\prime}$ & $5^{\prime}$-att gca ttt cct ggt gtt tc- $3^{\prime}$ \\
\hline MW0621 & $a p s R$ & $5^{\prime}$-gga tca agt gat gag tat gga a- $3^{\prime}$ & $5^{\prime}$-aca gca tct tgc caa gtc a- $3^{\prime}$ \\
\hline MM0816 & dltC & $5^{\prime}$-agc aga agt agc aga aaa tg- $3^{\prime}$ & $5^{\prime}$-gcc cac tca tct cta tca a- $3^{\prime}$ \\
\hline \multicolumn{4}{|c|}{ Construction of the mutant } \\
\hline MW1963 & $\operatorname{agr} A$ & $5^{\prime}$-gag gat cct tat gcg gtg ctt gag c-3' & $5^{\prime}$-caa agc ttt ggc gat tga cga caa a-3' \\
\hline \multicolumn{4}{|c|}{$\begin{array}{l}\text { Construction for } \\
\text { complementation }\end{array}$} \\
\hline MW0621 & $a p s R$ & $5^{\prime}$-gat aag ctt cag gag aaa ata tga a-3' & $5^{\prime}$-cca gga tcc cca gtt cat gcg aga ttt c- $3^{\prime}$ \\
\hline
\end{tabular}

${ }^{*}$ Gene ID in S. aureus MW2.

In the complementation experiment, we found that the phenotype of the aps mutant was restored by complementation with apsR, showing the decreased susceptibility to $\mathrm{hBD} 3$ and the increased expression of $d l t C$ compared with those of the aps mutant. Also, the phenotype of the agrA mutant was restored by complementation with agrA (Table 3). Furthermore, we found that complementation with agrA in the agr mutant decreased the expression of aps, while complementation with apsR in the aps mutant did not affect the expression of agr (data not shown).

Then, we constructed aps- and agr-inactivated mutants in another MRSA strain, TY34, to determine whether this result was specific to the MW2 strain. We obtained a result similar to that for MW2 (Table 3). The expression of dltC in the aps-inactivated mutant in the exponential phase was
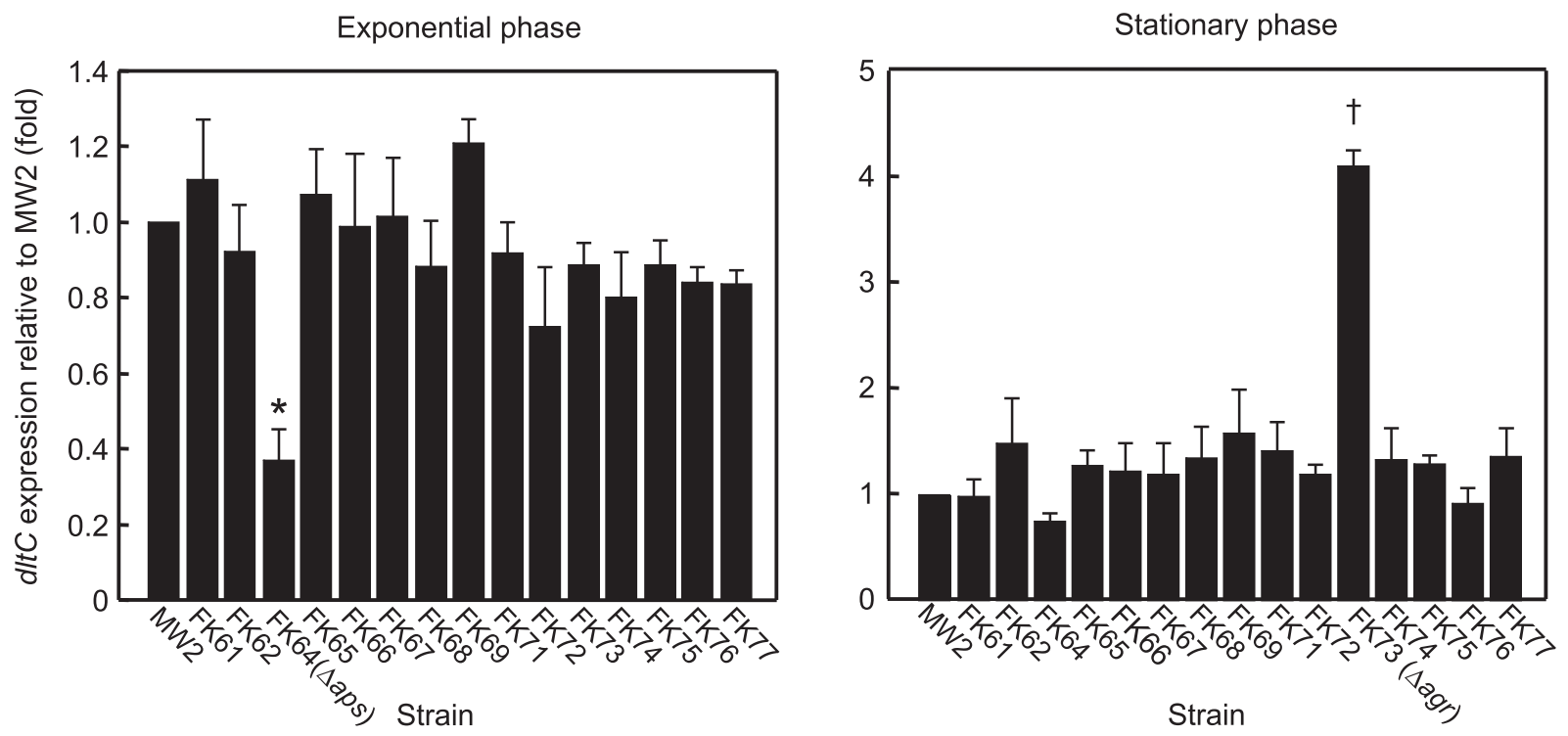

Fig. 1. $d / t C$ expression in the MW2 wild-type and its TCS mutants in the early exponential and stationary phases. Cells of MW2 and 15 TCS mutants were collected in the early exponential or stationary phase. $d / t C$ expression was measured by quantitative $\mathrm{PCR}$, as described in Methods. Data shown represent mean \pm SEM of triplicate measurements. *Significant decrease from the $d l t C$ expression of the wild-type strain MW2 as determined by Dunnett's test, $P<0.001$. + Significant increase from the dltC expression of the wild-type strain MW2 as determined by Dunnett's test, $P<0.001$. 
Table 3. Susceptibility to hBD3 and $d / t C$ expression in the exponential and stationary phases

\begin{tabular}{|c|c|c|c|c|c|}
\hline \multirow[t]{2}{*}{ Strain } & \multirow[t]{2}{*}{ Characteristics } & \multicolumn{2}{|c|}{ Survival rate $(\%)$ in the presence of $\mathrm{hBD}^{*}$} & \multicolumn{2}{|c|}{ dlt $C$ expression $\dagger$} \\
\hline & & EXP $\ddagger$ & STA $\$$ & EXP & STA \\
\hline MW2 & Clinical & 62.1 & 35.9 & 1.69 & 0.10 \\
\hline FK64 & $\Delta a p s$ & 28.8 & 32.3 & 0.35 & 0.07 \\
\hline MM11 & $\Delta a g r$ & 61.9 & 60.8 & 1.11 & 0.53 \\
\hline MM12 & apsR/FK64 & 54.8 & 51.6 & 1.26 & 0.26 \\
\hline MM14 & $\operatorname{agrA} / \mathrm{MM} 11$ & 28.4 & 29.7 & 0.74 & 0.06 \\
\hline RN4220 & Laboratory & 87.1 & 49.2 & 1.20 & 0.25 \\
\hline TY1355 & Clinical & 30.3 & 12.0 & 0.003 & 0.0012 \\
\hline TY1741 & Clinical & 84.3 & 53.0 & 0.91 & 0.17 \\
\hline TF2890 & Clinical & 73.7 & 38.0 & 1.41 & 0.16 \\
\hline TF2988 & Clinical & 82.0 & 25.7 & 1.23 & 0.12 \\
\hline TF3483 & Clinical & 83.0 & 54.0 & 0.78 & 0.22 \\
\hline TY34 & Clinical & 52.8 & 43.6 & 0.95 & 0.30 \\
\hline MM15 & $\Delta a p s$ & 34.2 & 45.0 & 0.26 & 0.24 \\
\hline MM16 & $\Delta a g r$ & 61.6 & 69.2 & 1.11 & 2.57 \\
\hline
\end{tabular}

*Survival rate was estimated as cell viability [c.f.u. (hBD3-treated)/c.f.u. (not treated)] expressed as a percentage. Data shown represent mean values of three independent experiments.

$\dagger d l t C$ expression was evaluated as a ratio with respect to gyrA expression in three independent experiments. $\ddagger$ EXP, exponential phase.

$\S S T A$, stationary phase.

lower than that of the wild-type, while its expression in the agr-inactivated mutant in the stationary phase was higher.

\section{dltC and mprF expression during growth}

S. aureus MW2 cells in early, mid- and late-exponential phases and in the stationary phase were collected (Fig. 2a), and then the mRNA expression of $\operatorname{dlt} C$ and $m p r F$ was analysed by quantitative PCR (Fig. 2b, c). The patterns of $d l t C$ and mprF expression during growth were quite similar, with no significant changes in the expression levels of the two genes in the exponential phase but drastic decreases in both in the stationary phase. We then investigated aps and agr expression during growth (Fig. 2d, e). The peak in aps expression was in the mid-exponential phase; this expression then decreased, especially in the stationary phase. In contrast, agr expression was quite low in the early and mid-exponential phase, and high in the stationary phase.

To analyse $d l t C$ and $m p r F$ expression in more detail, we investigated their expression in both the aps mutant and the agr mutant (Fig. 2b, c). The growth rate of the two mutants was similar to that of the wild-type. The aps mutant exhibited decreased $d l t C$ and $m p r F$ expression in the exponential phase compared with the wild-type, and showed expression levels that were similar to those of the wild-type in the stationary phase. The agr mutant showed similar expression to that of the wild-type in the early to mid-exponential phase, and increased levels of expression of both $d l t C$ and $m p r F$ in the late-exponential phase and, especially, in the stationary phase.
Since aps and agr affected $d l t / m p r F$ expression during growth, we then investigated whether the two TCSs affected each other (Fig. 2d, e). In the aps mutant, the agr expression pattern during growth was quite similar to that of the wild-type. On the other hand, aps expression was increased in the agr mutant compared with that in the wild-type. In particular, the aps expression level in the agr mutant increased in the stationary phase.

\section{Susceptibility to antimicrobial peptides during growth}

Since we found that the levels of $d l t C$ and $m p r F$ expression changed during growth, we analysed susceptibility to hBD3 $\left(0.5 \mu \mathrm{g} \mathrm{ml}^{-1}\right)$ in the wild-type (MW2 strain), the aps mutant and the agr mutant during growth (Fig. 3a). In the wild-type, susceptibility to hBD3 gradually increased during growth. In particular, the susceptibility to hBD3 in the stationary phase was higher (about half the level of survival compared with that in the early exponential phase) than that in the early exponential phase. The susceptibility to hBD3 of the aps mutant showed almost the same level of survival $(40 \%)$ throughout growth. This survival rate was significantly lower than that of the wild-type in the exponential phase, but was almost the same as that in the stationary phase. In contrast, the agr mutant showed almost the same survival rate as the wild-type in the early, mid- and late-exponential phases, while the survival rate in the stationary phase was higher than that of the wild-type. We also investigated the susceptibility to other betadefensins (hBD1 and hBD2) in the early exponential and 
(a)

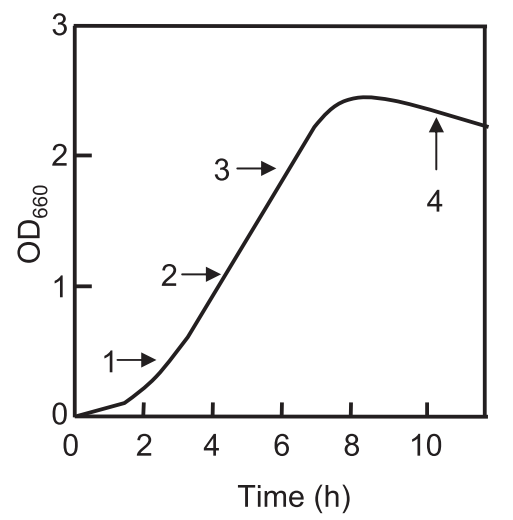

(b)

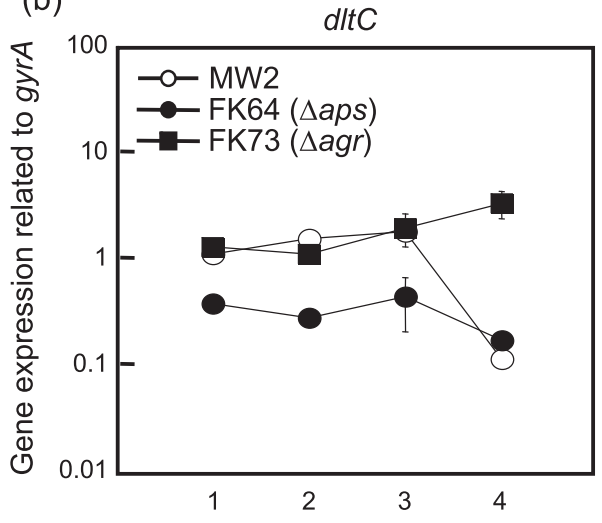

(d)

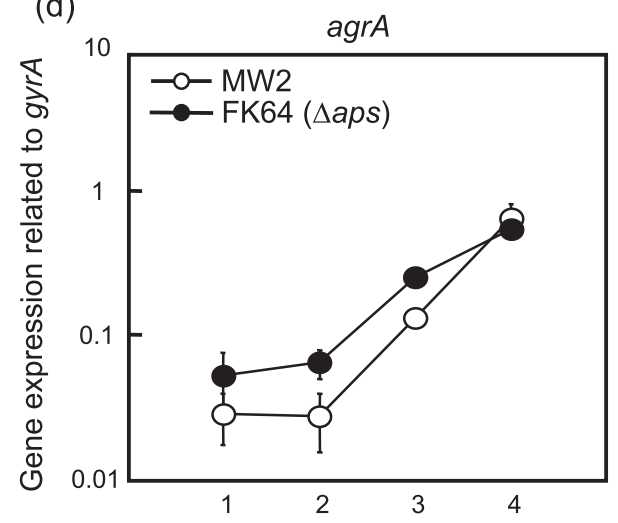

(c)

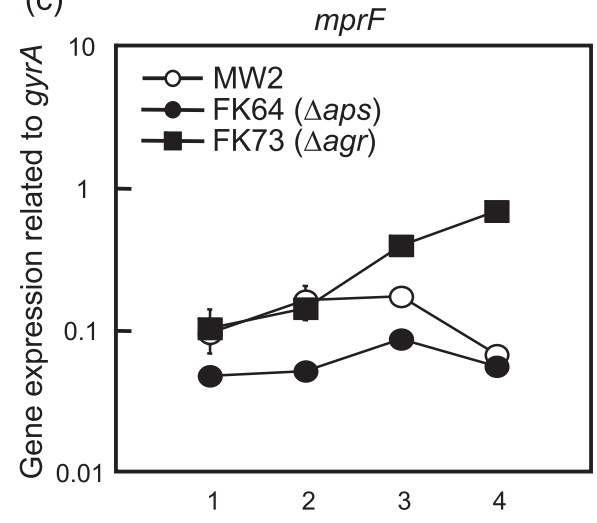

(e)

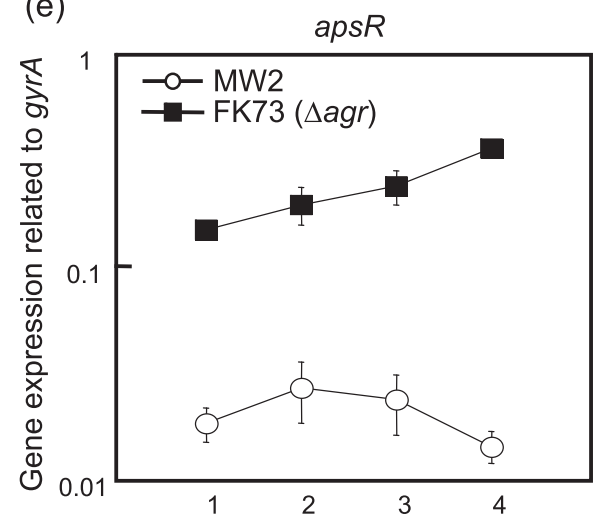

Fig. 2. $d l t, m p r F$, apsR and agrA expression in S. aureus during growth. (a) Growth curve of MW2 wild-type and derived strains. Cells of MW2, FK64 ( $\Delta a p s)$ and FK73 ( $\Delta$ agr) were collected at four time points, indicated by arrows (1, early exponential phase; 2, mid-exponential phase; 3, late-exponential phase; 4, stationary phase). dltC (b), $m p r F(\mathrm{c})$, agrA (d) and apsR (e) expression at the four points during growth was determined by quantitative PCR, as described in Methods. Data shown represent mean \pm SEM of triplicate measurements.

stationary phases. The results showed the same trend as that of hBD3, with a high susceptibility in the aps mutant in the exponential phase and a low susceptibility in the agr mutant in the stationary phase compared with those of the wild-type (Table 4).

\section{Cytochrome $c$ binding assay}

Bacterial cell surface charge is known to affect susceptibility to cationic antimicrobial peptides such as defensins. To evaluate the cell surface charge, we measured the cytochrome $c$ binding affinity of the wild-type and mutant cells during growth (Fig. 3b). Cytochrome $c$ is a cationic protein, and shows a high affinity for strongly negatively charged cells (Peschel et al., 1999). In the wild-type strain, the binding affinity in the exponential phase (early, $40.8 \%$; mid, $45.2 \%$ ) was lower than that in the stationary phase $(54.3 \%)$, implying that the bacterial cell surface charge in the stationary phase is more negative than that in the exponential phase. The binding affinity of the aps mutant in early and mid-exponential phase was significantly higher than that of the wild-type, while the affinity of the two strains was almost the same in the stationary phase because the wild-type exhibited increased binding affinity in the stationary phase. The agr mutant in the stationary phase showed a drastically decreased binding affinity compared with the wild-type. In summary, the cell surface charge of the aps mutant in the exponential phase was highly negative, and the charge of the agr mutant in the stationary phase was significantly lower than that of the wild-type.

\section{Susceptibility to cationic antibacterial agents during growth}

In the wild-type strain, susceptibility to the cationic antibacterial agents nisin, indolicidin, polymyxin B, gramicidin $S$, gentamicin and vancomycin in the exponential phase was lower than that in the stationary phase (Table 4), showing similar results in terms of the susceptibility to antimicrobial peptides. In addition, in the exponential 

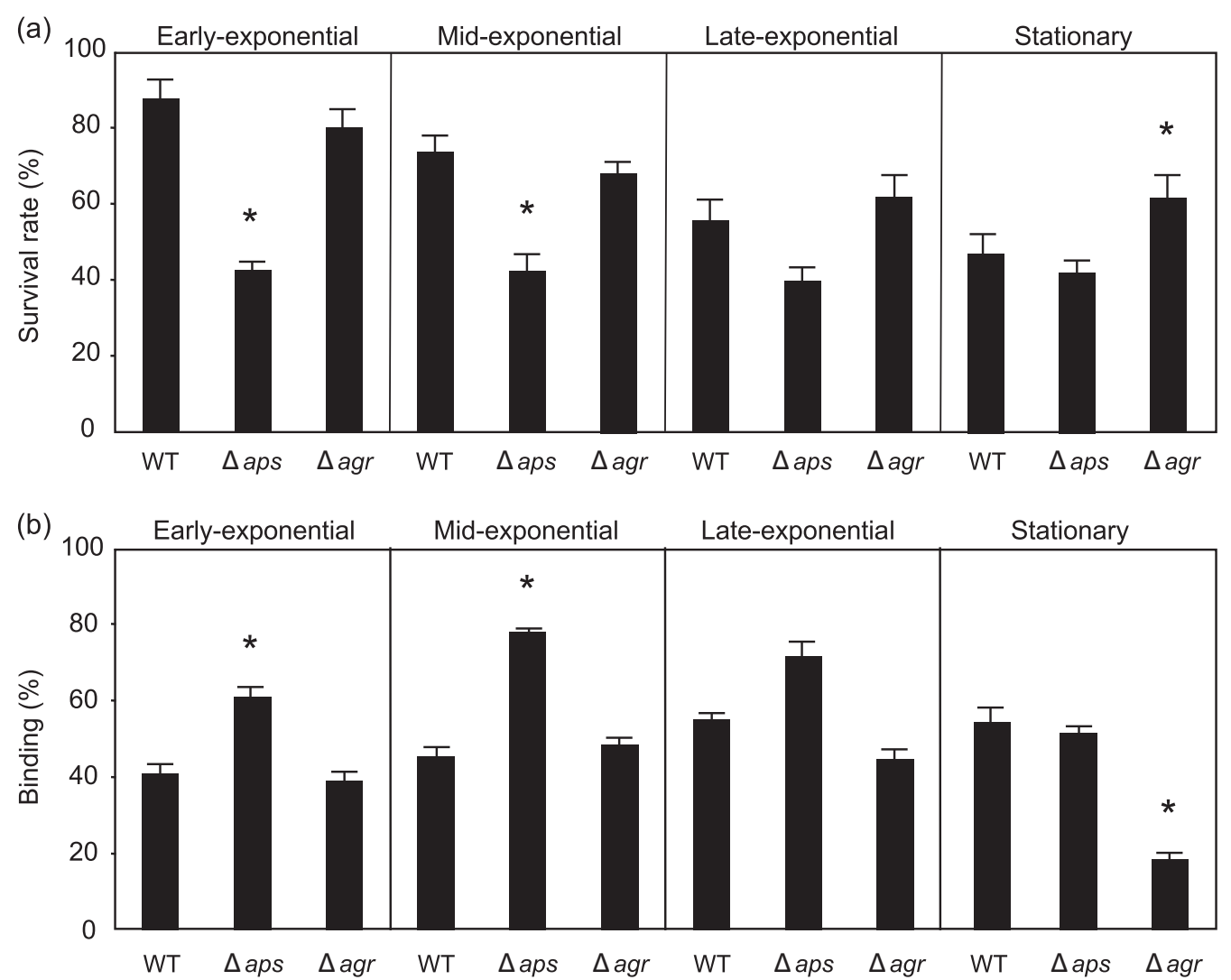

Fig. 3. Susceptibility to hBD3 and cytochrome $c$ binding affinity of $S$. aureus during growth. (a) Susceptibility to hBD3 of strains MW2, FK64 ( $\Delta$ aps) and FK73 ( $\Delta$ agr $)$ during growth. Bacterial cells $\left(10^{5}-10^{6}\right)$ in various phases were inoculated into $500 \mu l$ $10 \mathrm{mM}$ PB (pH 6.8) with or without $0.5 \mu \mathrm{g} \mathrm{hBD} 3 \mathrm{ml}^{-1}$ and incubated for $2 \mathrm{~h}$ at $37^{\circ} \mathrm{C}$. The antibacterial effect was calculated as the ratio of the number of surviving cells (survival rate, \%) to the total number of bacteria incubated in buffer without hBD3. Data shown represent mean + SEM of triplicate measurements. (b) Evaluation of bacterial cell surface charge during growth. The graph shows percentage binding of $250 \mu \mathrm{g}$ cytochrome $c \mathrm{ml}^{-1}$ after $10 \mathrm{~min}$ incubation with whole cells of strains MW2, FK64 $(\Delta a p s)$ and FK73 ( $\Delta$ agr $)$ at room temperature. Data shown represent mean + SEM of triplicate measurements. ${ }^{*} P<0.05$ (Dunnett's test). Calculations of statistical significance are for comparisons with the corresponding data for the MW2 wild-type.

phase the aps mutant showed increased susceptibility to cationic peptides compared with that of the wild-type; however, in the stationary phase, the susceptibility was almost the same in the wild-type and the mutant. The agr mutant in the stationary phase showed decreased susceptibility to cationic peptides compared with the wild-type.

\section{Correlation between susceptibility to antimicrobial peptides and dlt expression in clinical isolates}

Seven clinical isolates, including MW2 and TY34, and one laboratory strain were investigated (Table 3$)$. All strains tested showed that susceptibility to hBD3 $\left(0.5 \mu \mathrm{g} \mathrm{ml}^{-1}\right)$ in the exponential phase was lower than that in the stationary phase, although the ratio of the susceptibilities between the exponential and stationary phases differed among strains. In addition, in all strains, dltC expression in the exponential phase was higher than that in the stationary phase, indicating that susceptibility to hBD3 and dltC expression were correlated in all strains, as well as with the results for strain MW2. Strain TY1355, which exhibited a low level of $d l t$ expression compared with the other strains, showed high susceptibility to hBD3.

\section{Sensing antimicrobial peptides during growth}

It has been reported that the aps sytem in Staphylococcus epidermidis senses antimicrobial peptides such as hBD3, nisin and histatin (Li et al., 2007b). In S. aureus, the aps system also senses indolicidin, nisin and melitin and increases the expression of $d l t$, while the expression of $d l t$ in the presence of hBD3 is weak compared with that of indolicidin, nisin or melitin (Li et al., 2007a). Since we found that $d l t C$ expression changed during growth, we hypothesized that the sensing system in $S$. aureus changes during growth. Therefore, we analysed the ability to sense antimicrobial peptides in cells in the exponential and 
Table 4. Susceptibility to various antibacterial agents in S. aureus TCS mutants

\begin{tabular}{|c|c|c|c|c|c|c|c|}
\hline \multirow[t]{2}{*}{ Agent } & \multirow[t]{2}{*}{ Dose $\left(\mu \mathrm{g} \mathrm{ml}^{-1}\right)$} & \multicolumn{6}{|c|}{ Survival rate $(\%) \dagger$} \\
\hline & & \multicolumn{3}{|c|}{ Exponential phase } & \multicolumn{3}{|c|}{ Stationary phase } \\
\hline hBD1 & 2 & 37.9 & $13.3^{* *}$ & 42.2 & 26.1 & 30.7 & $69.0^{* *}$ \\
\hline hBD2 & 0.5 & 56.7 & $29.6^{* *}$ & 57.8 & 26.1 & 23.7 & $45.8^{*}$ \\
\hline Polymyxin B & 1 & 24.5 & $8.5^{*}$ & 32.6 & 15.3 & 15.7 & $28.5^{*}$ \\
\hline Gramicidin S & 1 & 57.4 & $23.8^{*}$ & 51.6 & 28.6 & 26.3 & $54.4^{*}$ \\
\hline Gentamicin & 4 & 43.8 & $6.7^{*}$ & 40.7 & 29.2 & 32.6 & $60.0^{* *}$ \\
\hline Vancomycin & 2 & 46.4 & $23.6^{*}$ & 41.9 & 26.4 & 35.0 & $70.5^{* *}$ \\
\hline
\end{tabular}

$\dagger$ Survival rate was estimated as cell viability [c.f.u. (antibacterial agent-treated)/c.f.u. (not treated)] expressed as a percentage. Data shown represent mean values of three independent experiments.

$\$ \mathrm{WT}$, wild-type.

${ }^{*} P<0.05,{ }^{* *} P<0.01$ (Dunnett's test). Calculations of statistical significance are for comparison with the corresponding data for the MW2 wild-type.

stationary phases. Before assaying, we confirmed that $2.5 \mu \mathrm{g} \mathrm{hBD} 3 \mathrm{ml}^{-1}$ had no significant effect on cell viability.

We investigated the $d l t C$ expression of the wild-type and aps mutant in the exponential and stationary phases (Fig. 4). We consider the difference from the earlier results ( $\mathrm{Li}$ et al., 2007b) (weak sensing of hBD3 in S. aureus) to be due to the phase of the bacterial cells and/or the conditions of the assay $(10 \mathrm{mM}$ phosphate buffer in this study, $10 \mathrm{mM}$ phosphate buffer with $100 \mathrm{mM} \mathrm{NaCl}$ in the earlier study). We found that hBD3 induced $d l t C$ expression of the wild-type in the exponential phase, but found no induction in the aps mutant. Also, we found that dltC expression of the wild-type in buffer without hBD3 was decreased to almost half after $30 \mathrm{~min}$ incubation, while that of the aps mutant was not decreased (data not shown). In contrast, $d l t C$ expression of both strains in the stationary phase was not induced by hBD3. In addition, we used hBD1 and hBD2 as inducers, and obtained similar results to those for hBD3 (Fig. 4). The aps expression of the wildtype in the exponential phase was also induced by hBD3, but its expression in the stationary phase was not induced (data not shown).
Exponential phase

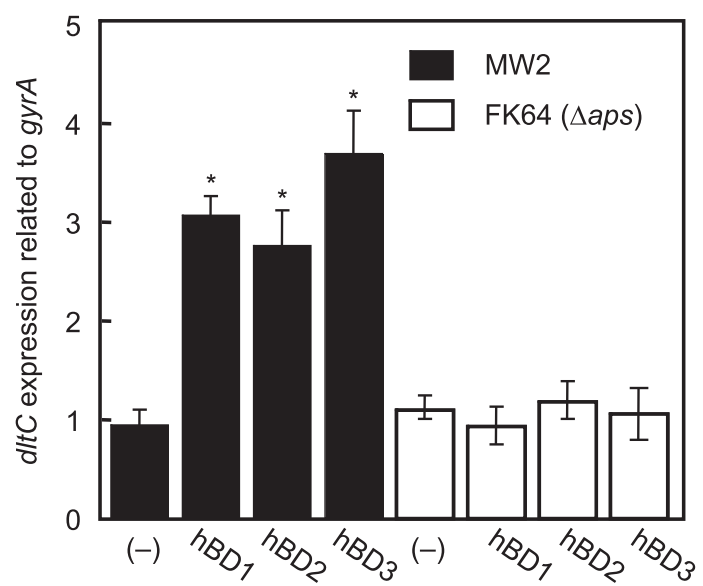

Stationary phase

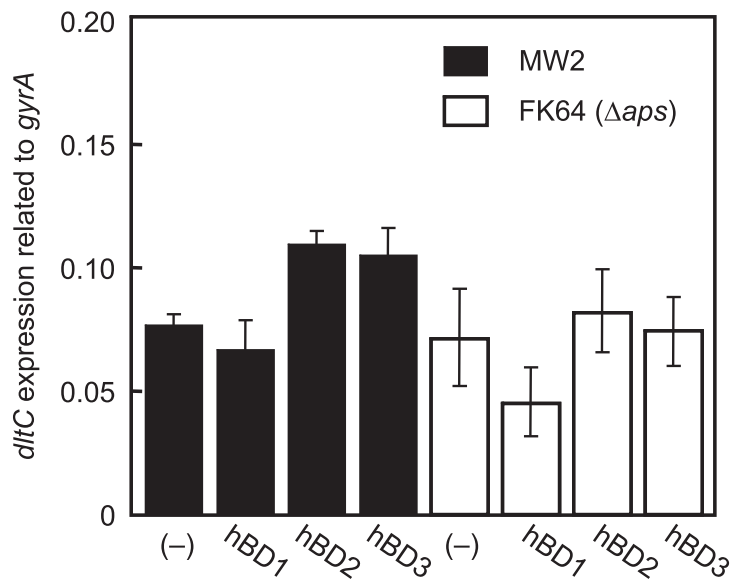

Fig. 4. Induction of dlt expression by sensing of hBD via aps. MW2 wild-type and aps mutant cells were collected in the early exponential and stationary phases. Cells were suspended in PB to give a concentration of $10^{9}$ cells $\mathrm{ml}^{-1}$. Concentrations of $10 \mu \mathrm{g} \mathrm{hBD} 1 \mathrm{ml}^{-1}, 2.5 \mu \mathrm{g} \mathrm{hBD} 2 \mathrm{ml}^{-1}$ and $2.5 \mu \mathrm{g} \mathrm{hBD} 3 \mathrm{ml}^{-1}$ were added separately to bacterial suspensions and incubated for $30 \mathrm{~min}$ at $37^{\circ} \mathrm{C}$. Calculations of statistical significance are for comparisons with the corresponding data for $\mathrm{MW} 2$. $^{*} P<0.01$ (Dunnett's test). Data shown represent mean \pm SEM of triplicate measurements. (-), No hBD added. 


\section{DISCUSSION}

In this study, we initially showed that the charge of the bacterial cell surface in $S$. aureus changed during growth. Dlt and MprF have been reported to be major contributors to a decreased negative charge of cell surfaces because these factors are associated with the addition of amino acids ( $d l t$ for alanine and $m p r F$ for lysine) to teichoic acids and phosphatidylglycerol, respectively (Collins et al., 2002; Peschel et al., 1999, 2001). Alanylation of teichoic acids in cell walls and lysyl-phosphatidylglycerol in membranes confer a positive charge upon bacterial cell surfaces, which results in a shift to a weak negative charge on the cell surface (Peschel et al., 1999, 2001). Earlier reports and our present findings demonstrate that aps/gra, a TCS in $S$. aureus, positively regulates the expression of $d l t$ and $m p r F$ (Kraus et al., 2008; Li et al., 2007a). In addition, our new finding is that aps/gra expression is also regulated by $a g r$, which has a central role in the quorum-sensing system (Novick \& Geisinger, 2008); this implies that agr also regulates the expression of $d l t$ and $m p r F$ by controlling aps. Since agr expression is dependent on cell density (Cheung et al., 2004; Novick, 2003; Novick \& Geisinger, 2008), agr expression gradually increases during growth, showing high expression in the stationary phase and low expression in the exponential phase. Our results showed that aps expression during growth decreases gradually in an inverse relationship with the level of agr expression. In addition, aps expression was significantly increased in the agr mutant, especially in the stationary phase. These results indicate that aps is negatively regulated by agr, and is mainly expressed in the exponential phase.
Agr, a quorum-sensing system, is involved in the expression of many factors, including virulence factors mediated by RNAIII. RNAIII has been demonstrated to directly upregulate hla (alpha-haemolysin) (Morfeldt et al., 1995), and downregulate spa (protein A) (Huntzinger et al., 2005) and the transcription factor rot responsible for the repression of toxins (Geisinger et al., 2006). RNAIII binds to the target mRNA directly, resulting in the up- or downregulation of gene expression. However, the precise mechanism of the expression of other virulence factors mediated by the agr system is still unknown. The mechanism of aps regulation by agr also needs further investigation. Since aps is a positive regulator of $d l t$ and $m p r F$ (Kraus et al., 2008; Li et al., 2007a), S. aureus cells in the stationary phase are considered to be highly susceptible to antimicrobial peptides, owing to the strong negative charge of the cell surface caused by decreased $d l t$ and mprF expression through the $a g r-a p s$ pathway. Moreover, susceptibility to several positively charged agents has also been shown to be growth-dependent. Therefore, we conclude that, in $S$. aureus, susceptibility to some positively charged antibacterial agents changes during growth.

Since aps expression was higher in the exponential phase than in the stationary phase, we consider that the ability to sense antimicrobial peptides is also growth phasedependent. Our results showed that the aps system to sense hBDs (hBD1-3) only functioned in the exponential phase, and not in the stationary phase. We also identified an ability to sense alpha-defensin and indolicidin in $S$. aureus cells in the exponential phase, but not in the stationary phase (data not shown). These results indicate
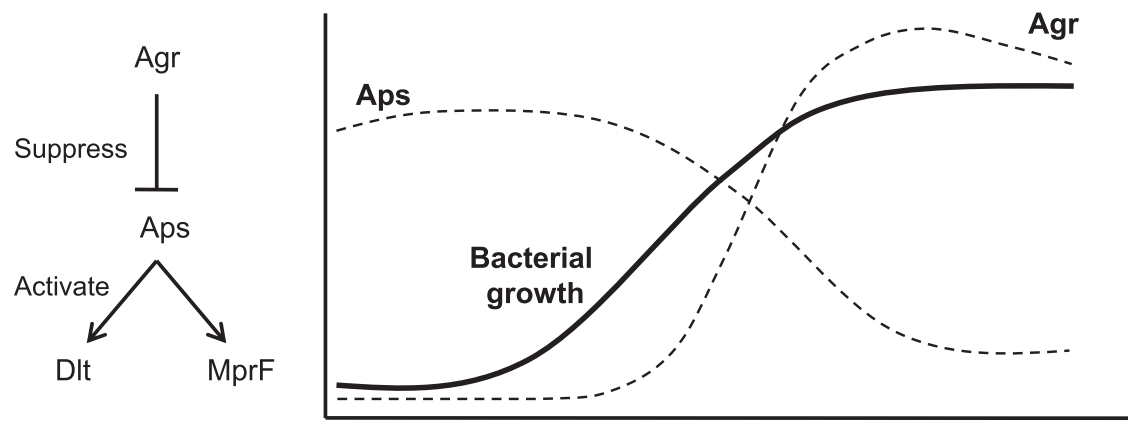

Bacterial growth
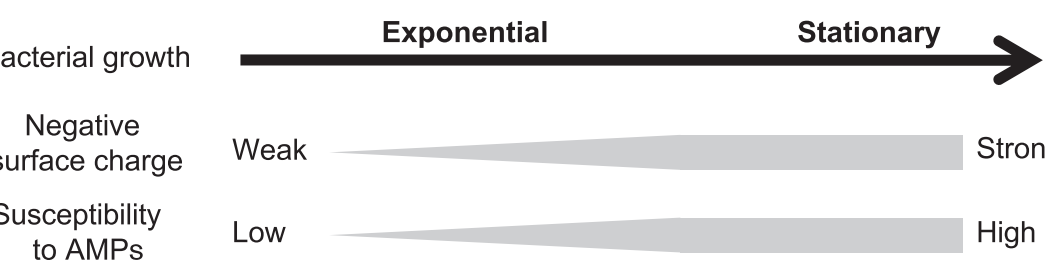

Weak

Strong

Low

High

Sensing ability

Strong

Weak

Fig. 5. Bacterial cell surface charge is regulated during growth. Gene products involved in the regulation of surface charge are indicated (upper left), and a model for aps and agr expression during growth is also shown (upper right). Cell surface charge, susceptibility to antimicrobial peptides (AMPs) and ability to sense antimicrobial peptides change during growth. 
that the induction of $d l t$ expression by antimicrobial peptides through the aps system is growth phase-dependent in S. aureus.

Besides affecting susceptibility to antimicrobial peptides, bacterial cell surface charge has been reported to affect several other biological activities, such as adhesion to biomaterials and mammalian cells, and phagocytic activity (Collins et al., 2002; Gottenbos et al., 2001; Gross et al., 2001; Peschel et al., 2001). In particular, dlt plays a central role in the regulation of cell surface charge. The absence of $d l$ in $S$. aureus results in a high susceptibility to being killed by neutrophils and also reduces the ability to colonize plastic or glass surfaces, a factor in catheterassociated infection (Collins et al., 2002; Gross et al., 2001). In addition, it has been found that a dlt mutant is highly susceptible to human phospholipase $\mathrm{A}_{2}$, a cationic protein that exhibits antibacterial activity against $S$. aureus, owing to a strong surface negative charge (Koprivnjak et al., 2002). Furthermore, $d l t$ in group A streptococci has been found to promote survival in neutrophils and invasion of epithelial cells (Kristian et al., 2005), and dlt in Streptococcus agalactiae and Listeria monocytogenes is associated with susceptibility to phagocytic cells (Abachin et al., 2002; Poyart et al., 2003). Taken together with our results in the present study, these findings suggest that in $S$. aureus not only susceptibility to antimicrobial peptides but also other biological activities change during growth.

As for antibiotic susceptibility, we demonstrated increased susceptibility to several cationic agents in the aps mutant, which implies that the charge of the bacterial cell surface affects susceptibility to antibiotics. Similarly, daptomycin susceptibility has been shown to be affected by cell surface charge mediated by mprF and dlt (Yang et al., 2009a, b). Aps/Gra has been found to be related to susceptibility to glycopeptides in vancomycin-intermediate S. aureus (VISA), owing to transporters $(\mathrm{rraFG})$ located immediately downstream of aps/gra and regulated by aps/gra (Howden et al., 2008; Meehl et al., 2007). Inactivation of aps in VISA has been demonstrated to increase susceptibility to vancomycin, because $v r a F G$ expression is suppressed. Although $v r a F G$ is strongly associated with vancomycin susceptibility, a more negatively charged cell surface in an aps/gra mutant also increased susceptibility to positively charged vancomycin (Table 4).

In conclusion, we have demonstrated that $S$. aureus cell surface charge is related to the expression of $d l t$ and $m p r F$, which are tightly regulated by aps and agr during growth (Fig. 5). It is interesting that not only many virulence factors but also cell surface charge depend on the growth phase and are mediated by the agr system. We have also shown that susceptibility to antimicrobial peptides and the ability to sense antimicrobial peptides change during growth. Our study indicates that bacterial cell surface charge is tightly regulated during growth, and that some features associated with surface charge are dependent on the growth phase.

\section{ACKNOWLEDGEMENTS}

This work was supported by a grant-in-aid for scientific research from the Health and Labor Sciences Research Grants from the Ministry of Health and Welfare of Japan.

\section{REFERENCES}

Abachin, E., Poyart, C., Pellegrini, E., Milohanic, E., Fiedler, F., Berche, P. \& Trieu-Cuot, P. (2002). Formation of D-alanyllipoteichoic acid is required for adhesion and virulence of Listeria monocytogenes. Mol Microbiol 43, 1-14.

Baba, T., Takeuchi, F., Kuroda, M., Yuzawa, H., Aoki, K., Oguchi, A., Nagai, Y., Iwama, N., Asano, K., Naimi, T., Kuroda, H., Cui, L., Yamamoto, K. \& Hiramatsu, K. (2002). Genome and virulence determinants of high virulence community-acquired MRSA. Lancet 359, 1819-1827.

Braff, M. H., Jones, A. L., Skerrett, S. J. \& Rubens, C. E. (2007). Staphylococcus aureus exploits cathelicidin antimicrobial peptides produced during early pneumonia to promote staphylokinasedependent fibrinolysis. J Infect Dis 195, 1365-1372.

Cheung, A. L., Bayer, A. S., Zhang, G., Gresham, H. \& Xiong, Y. Q. (2004). Regulation of virulence determinants in vitro and in vivo in Staphylococcus aureus. FEMS Immunol Med Microbiol 40, 1-9.

Collins, L. V., Kristian, S. A., Weidenmaier, C., Faigle, M., Van Kessel, K. P., Van Strijp, J. A., Götz, F., Neumeister, B. \& Peschel, A. (2002). Staphylococcus aureus strains lacking D-alanine modifications of teichoic acids are highly susceptible to human neutrophil killing and are virulence attenuated in mice. J Infect Dis 186, 214-219.

Cunliffe, R. N. (2003). Alpha-defensins in the gastrointestinal tract. Mol Immunol 40, 463-467.

Deurenberg, R. H., Vink, C., Kalenic, S., Friedrich, A. W., Bruggeman, C. A. \& Stobberingh, E. E. (2007). The molecular evolution of methicillin-resistant Staphylococcus aureus. Clin Microbiol Infect 13, 222-235.

Fellermann, K., Wehkamp, J., Herrlinger, K. R. \& Stange, E. F. (2003a). Crohn's disease: a defensin deficiency syndrome? Eur J Gastroenterol Hepatol 15, 627-634.

Fellermann, K., Wehkamp, J. \& Stange, E. F. (2003b). Antimicrobial peptides in the skin. $N$ Engl J Med 348, 361-363, author reply 361363.

Foster, T. J. (2004). The Staphylococcus aureus "superbug". J Clin Invest 114, 1693-1696.

Foster, T. J. (2005). Immune evasion by staphylococci. Nat Rev Microbiol 3, 948-958.

Ganz, T. \& Lehrer, R. I. (1995). Defensins. Pharmacol Ther 66, 191205.

Ganz, T., Selsted, M. E., Szklarek, D., Harwig, S. S., Daher, K., Bainton, D. F. \& Lehrer, R. I. (1985). Defensins. Natural peptide antibiotics of human neutrophils. J Clin Invest 76, 1427-1435.

Geisinger, E., Adhikari, R. P., Jin, R., Ross, H. F. \& Novick, R. P. (2006). Inhibition of rot translation by RNAIII, a key feature of agr function. Mol Microbiol 61, 1038-1048.

Gottenbos, B., Grijpma, D. W., van der Mei, H. C., Feijen, J. \& Busscher, H. J. (2001). Antimicrobial effects of positively charged surfaces on adhering Gram-positive and Gram-negative bacteria. $J$ Antimicrob Chemother 48, 7-13.

Gross, M., Cramton, S. E., Götz, F. \& Peschel, A. (2001). Key role of teichoic acid net charge in Staphylococcus aureus colonization of artificial surfaces. Infect Immun 69, 3423-3426. 
Grundmann, H., Aires-de-Sousa, M., Boyce, J. \& Tiemersma, E. (2006). Emergence and resurgence of meticillin-resistant Staphylococcus aureus as a public-health threat. Lancet 368, 874-885.

Howden, B. P., Stinear, T. P., Allen, D. L., Johnson, P. D., Ward, P. B. \& Davies, J. K. (2008). Genomic analysis reveals a point mutation in the two-component sensor gene graS that leads to intermediate vancomycin resistance in clinical Staphylococcus aureus. Antimicrob Agents Chemother 52, 3755-3762.

Huntzinger, E., Boisset, S., Saveanu, C., Benito, Y., Geissmann, T., Namane, A., Lina, G., Etienne, J., Ehresmann, B. \& other authors (2005). Staphylococcus aureus RNAIII and the endoribonuclease III coordinately regulate spa gene expression. EMBO J 24, 824-835.

Jin, T., Bokarewa, M., Foster, T., Mitchell, J., Higgins, J. \& Tarkowski, A. (2004). Staphylococcus aureus resists human defensins by production of staphylokinase, a novel bacterial evasion mechanism. J Immunol 172, 1169-1176.

Komatsuzawa, H., Ohta, K., Fujiwara, T., Choi, G. H., Labischinski, H. \& Sugai, M. (2001). Cloning and sequencing of the gene, $f m t C$, which affects oxacillin resistance in methicillin-resistant Staphylococcus aureus. FEMS Microbiol Lett 203, 49-54.

Komatsuzawa, H., Fujiwara, T., Nishi, H., Yamada, S., Ohara, M., McCallum, N., Berger-Bächi, B. \& Sugai, M. (2004). The gate controlling cell wall synthesis in Staphylococcus aureus. Mol Microbiol 53, 1221-1231.

Koprivnjak, T., Peschel, A., Gelb, M. H., Liang, N. S. \& Weiss, J. P. (2002). Role of charge properties of bacterial envelope in bactericidal action of human group IIA phospholipase $\mathrm{A}_{2}$ against Staphylococcus aureus. J Biol Chem 277, 47636-47644.

Kraus, D., Herbert, S., Kristian, S. A., Khosravi, A., Nizet, V., Götz, F. \& Peschel, A. (2008). The GraRS regulatory system controls Staphylococcus aureus susceptibility to antimicrobial host defenses. BMC Microbiol 8, 85.

Kreiswirth, B. N., Löfdahl, S., Betley, M. J., O'Reilly, M., Schlievert, P. M., Bergdoll, M. S. \& Novick, R. P. (1983). The toxic shock syndrome exotoxin structural gene is not detectably transmitted by a prophage. Nature 305, 709-712.

Kristian, S. A., Datta, V., Weidenmaier, C., Kansal, R., Fedtke, I., Peschel, A., Gallo, R. L. \& Nizet, V. (2005). D-Alanylation of teichoic acids promotes group A Streptococcus antimicrobial peptide resistance, neutrophil survival, and epithelial cell invasion. J Bacteriol 187, 6719-6725.

Larrick, J. W., Hirata, M., Balint, R. F., Lee, J., Zhong, J. \& Wright, S. C. (1995). Human CAP18: a novel antimicrobial lipopolysaccharidebinding protein. Infect Immun 63, 1291-1297.

Lehrer, R. I. \& Ganz, T. (1999). Antimicrobial peptides in mammalian and insect host defence. Curr Opin Immunol 11, 23-27.

Li, M., Cha, D. J., Lai, Y., Villaruz, A. E., Sturdevant, D. E. \& Otto, M. (2007a). The antimicrobial peptide-sensing system aps of Staphylococcus aureus. Mol Microbiol 66, 1136-1147.

Li, M., Lai, Y., Villaruz, A. E., Cha, D. J., Sturdevant, D. E. \& Otto, M. (2007b). Gram-positive three-component antimicrobial peptidesensing system. Proc Natl Acad Sci U S A 104, 9469-9474.

Lowy, F. D. (1998). Staphylococcus aureus infections. N Engl J Med 339, 520-532.

Luong, T. T. \& Lee, C. Y. (2006). The arl locus positively regulates Staphylococcus aureus type 5 capsule via an $m g r A$-dependent pathway. Microbiology 152, 3123-3131.

Manders, S. M. (1998). Toxin-mediated streptococcal and staphylococcal disease. J Am Acad Dermatol 39, 383-398, quiz 399-400.

Matsuo, M., Kato, F., Oogai, Y., Kawai, T., Sugai, M. \& Komatsuzawa, H. (2010). Distinct two-component systems in methicillin-resistant
Staphylococcus aureus can change the susceptibility to antimicrobial agents. J Antimicrob Chemother 65, 1536-1537.

Meehl, M., Herbert, S., Götz, F. \& Cheung, A. (2007). Interaction of the GraRS two-component system with the VraFG ABC transporter to support vancomycin-intermediate resistance in Staphylococcus aureus. Antimicrob Agents Chemother 51, 2679-2689.

Midorikawa, K., Ouhara, K., Komatsuzawa, H., Kawai, T., Yamada, S., Fujiwara, T., Yamazaki, K., Sayama, K., Taubman, M. A. \& other authors (2003). Staphylococcus aureus susceptibility to innate antimicrobial peptides, beta-defensins and CAP18, expressed by human keratinocytes. Infect Immun 71, 3730-3739.

Morfeldt, E., Taylor, D., von Gabain, A. \& Arvidson, S. (1995). Activation of alpha-toxin translation in Staphylococcus aureus by the trans-encoded antisense RNA, RNAIII. EMBO J 14, 4569-4577.

Novick, R. P. (2003). Autoinduction and signal transduction in the regulation of staphylococcal virulence. Mol Microbiol 48, 1429-1449. Novick, R. P. \& Geisinger, E. (2008). Quorum sensing in staphylococci. Annu Rev Genet 42, 541-564.

Ong, P. Y., Ohtake, T., Brandt, C., Strickland, I., Boguniewicz, M., Ganz, T., Gallo, R. L. \& Leung, D. Y. (2002). Endogenous antimicrobial peptides and skin infections in atopic dermatitis. N Engl J Med 347, 1151-1160.

Ouhara, K., Komatsuzawa, H., Kawai, T., Nishi, H., Fujiwara, T., Fujiue, Y., Kuwabara, M., Sayama, K., Hashimoto, K. \& Sugai, M. (2008). Increased resistance to cationic antimicrobial peptide LL-37 in methicillin-resistant strains of Staphylococcus aureus. J Antimicrob Chemother 61, 1266-1269.

Peschel, A., Otto, M., Jack, R. W., Kalbacher, H., Jung, G. \& Götz, F. (1999). Inactivation of the dlt operon in Staphylococcus aureus confers sensitivity to defensins, protegrins, and other antimicrobial peptides. J Biol Chem 274, 8405-8410.

Peschel, A., Jack, R. W., Otto, M., Collins, L. V., Staubitz, P., Nicholson, G., Kalbacher, H., Nieuwenhuizen, W. F., Jung, G. \& other authors (2001). Staphylococcus aureus resistance to human defensins and evasion of neutrophil killing via the novel virulence factor MprF is based on modification of membrane lipids with L-lysine. J Exp Med 193, 1067-1076.

Poyart, C., Pellegrini, E., Marceau, M., Baptista, M., Jaubert, F., Lamy, M. C. \& Trieu-Cuot, P. (2003). Attenuated virulence of Streptococcus agalactiae deficient in D-alanyl-lipoteichoic acid is due to an increased susceptibility to defensins and phagocytic cells. Mol Microbiol 49, 1615-1625.

Pütsep, K., Carlsson, G., Boman, H. G. \& Andersson, M. (2002). Deficiency of antibacterial peptides in patients with morbus Kostmann: an observation study. Lancet 360, 1144-1149.

Ramanathan, B., Davis, E. G., Ross, C. R. \& Blecha, F. (2002). Cathelicidins: microbicidal activity, mechanisms of action, and roles in innate immunity. Microbes Infect 4, 361-372.

Rooijakkers, S. H., van Kessel, K. P. \& van Strijp, J. A. (2005). Staphylococcal innate immune evasion. Trends Microbiol 13, 596601.

Sau, S., Sun, J. \& Lee, C. Y. (1997). Molecular characterization and transcriptional analysis of type 8 capsule genes in Staphylococcus aureus. J Bacteriol 179, 1614-1621.

Selsted, M. E. \& Ouellette, A. J. (2005). Mammalian defensins in the antimicrobial immune response. Nat Immunol 6, 551-557.

Sieprawska-Lupa, M., Mydel, P., Krawczyk, K., Wójcik, K., Puklo, M., Lupa, B., Suder, P., Silberring, J., Reed, M. \& other authors (2004). Degradation of human antimicrobial peptide LL-37 by Staphylococcus aureus-derived proteinases. Antimicrob Agents Chemother 48, 46734679. 
Wehkamp, J., Fellermann, K., Herrlinger, K. R., Baxmann, S., Schmidt, K., Schwind, B., Duchrow, M., Wohlschläger, C., Feller, A. C. \& Stange, E. F. (2002). Human beta-defensin 2 but not betadefensin 1 is expressed preferentially in colonic mucosa of inflammatory bowel disease. Eur J Gastroenterol Hepatol 14, 745-752.

Yang, S. J., Xiong, Y. Q., Dunman, P. M., Schrenzel, J., François, P., Peschel, A. \& Bayer, A. S. (2009a). Regulation of $m p r F$ in daptomycinnonsusceptible Staphylococcus aureus strains. Antimicrob Agents Chemother 53, 2636-2637.
Yang, S. J., Kreiswirth, B. N., Sakoulas, G., Yeaman, M. R., Xiong, Y. Q., Sawa, A. \& Bayer, A. S. (2009b). Enhanced expression of dltABCD is associated with the development of daptomycin nonsusceptibility in a clinical endocarditis isolate of Staphylococcus aureus. J Infect Dis 200, 1916-1920.

Zaiou, M. \& Gallo, R. L. (2002). Cathelicidins, essential gene-encoded mammalian antibiotics. J Mol Med 80, 549-561.

Edited by: H. Ingmer 